\title{
Java and loT (Internet of Things): Automating the Industrial Economy
}

\author{
Suyash Kumar Singh ${ }^{1}$, Sanjiv Tokekar ${ }^{1}$, Abhishek Raghuvanshi ${ }^{2}$, Umesh Kumar Singh ${ }^{3}$ \\ ${ }^{1}$ Institute of Engineering \& Technology, DAVV, Indore, MP, India \\ ${ }^{2}$ Mahakal Institute of Technology, Ujjain, MP, India \\ ${ }^{3}$ School of Engineering \& Technology, Vikram University, Ujjain, MP, India
}

\begin{abstract}
Internet of Things (IoT) is derived from IT (Information Technology) and OT (Operational technology). Ultimately, IoT is using the information technology to control the physical devices of manufacturing sector for better resource utilization and creating new revenue through new products and services. IoT is a global network, which consists of objects, capable of collecting massive data in accurate and speedy manner, processing that data $\&$ then sharing that data with other connected devices for real time action. Industrial Internet of Things (IIoT) is an application of IoT in manufacturing sector. IIoT will rapidly transform gas, mining, oil, agriculture, healthcare sectors. IIoT is the torch bearer for fourth industrial revolution, named Industry 4.0. This paper shows that java is the single positioned platform to cater the needs of IoT applications. In addition, this paper makes use of IoT world forum survey to provide opportunities and challenges in adaption of industrial internet in systematic manner. This paper reviews the current progress of industrial internet \& provides a summary of state-of-art of Internet of Things (IoT) in industries.
\end{abstract}

\section{Keywords}

Internet of Things (IoT), JIoT, Industrial Internet of Things (IIoT), Wireless Sensor, Industry 4.0.

\section{INTRODUCTION}

IoT is a system of interrelated computing devices, humans, animals, mechanical machines or digital machines. These all are provided a unique identifier and the capability to transfer data over a network. It does not require human to human or human to machine interaction. It is a form of machine to machine interaction. The term IoT (Internet of Things) was first mentioned by Kevin Ashton, Executive Director, AutoID center MIT, in a presentation at Proctor \& Gamble in 1999.

Ultimately, IoT is collecting massive amount of data from a exponentially increasing network of devices cum sensors, sending that data to central cloud based service, processing that data, and sharing the output with other computing devices to make real time decisions. Gartner [1] declared Internet of Things as the most discussed technology of 2014.

In Internet of Things, a thing can be a heart monitor, an animal with a biochip transponder, an automobile with sensor that alerts driver when temperature is high, or tyre pressure is high, when a particular part is required to be repaired or changed etc. Basically a thing in the Internet of Things is any manmade object or natural object with an IP address and data transfer ability over a network. It is shown below in figure 1 .

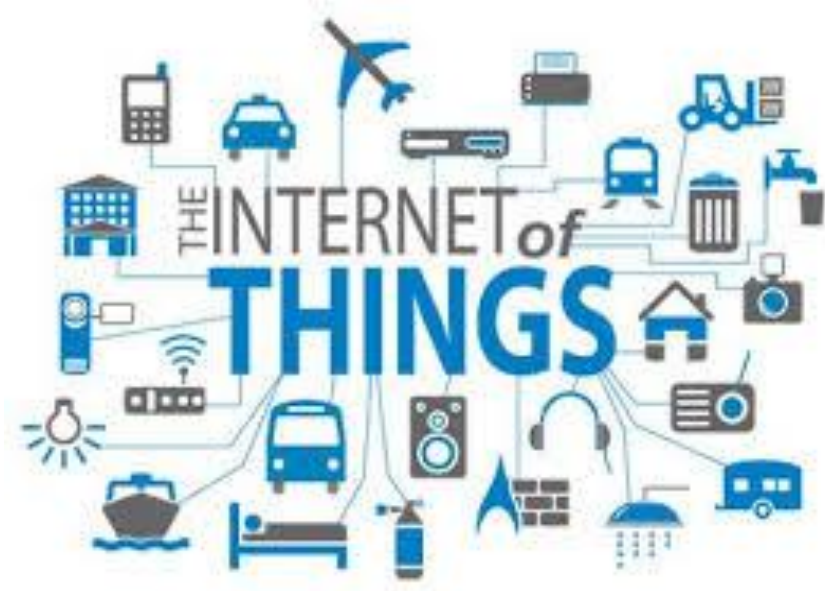

Fig 1: Internet of Things [IoT]

The basic building blocks of IoT are sensors, IoT platform, Cloud server, mobile application. It is shown in figure 2.

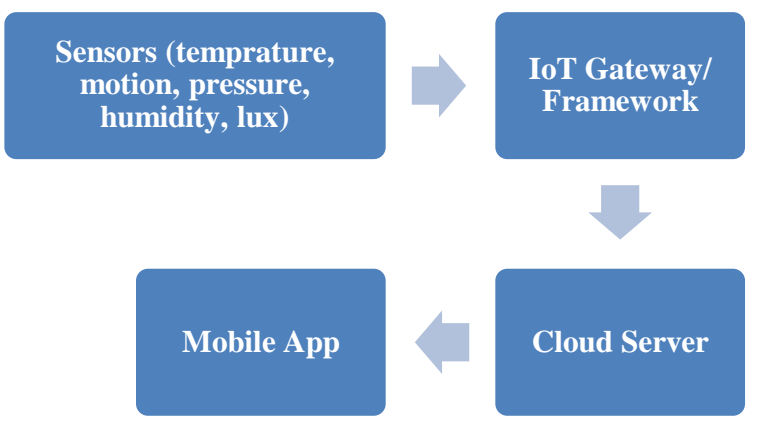

Fig 2: Basic building Blocks of IoT

The sensors are at the grass root level. They monitor temperature, motion, pressure, lux and humidity. There is a IoT framework, which collects data from sensors. Then this framework sends that data to centralized cloud server. Cloud server processes all data \& share results with connected mobile app. All the connections in this whole process are wireless.

\section{JIOT (JAVA \& IOT)}

Java is a natural choice for developing emerging IoT technologies. As interoperability is the main feature of Java, which is much needed in IoT. As an open platform, Java provides code portability, the application is written once and it 
can be prototyped on different hardware platforms like: Raspberry Pi, Edison Board or any small microcontroller device. Oracle Java has the ability to run on a wide range of devices from a mobile to embedded systems with low cpu power and low memory to servers with high cpu capacity and voluminous memory. Java provides a modern secure development platform to develop deploy and maintain applications to cater IoT needs. No other platform is better positioned to cater Industrial Internet of Things.

IEEE spectrum 2014 [2] declared Java as the top most programming language. Java has a large pool of around 9 million java developers around the world, who are developing java applications to connect the world.

\section{RANK 1. JAVA (WMD/100) \\ RANK 2. C (MDE/95.9) \\ RANK 3. C++ (MDE 93.9) \\ RANK 4. C\# (WMD 93) \\ RANK 5. PYTHON (WD 92.1) \\ RANK 6. JAVA SCRIPT (WM 86.3) \\ Fig 3: Java is Top Programming Language [source; IEEE Spectrum 2014 top ranked programming language] \\ 3. IIOT (INDUSTRIAL INTERNET OF THINGS) - AUTOMATING THE INDUSTRIAL ECONOMY}

IIoT is a part of the Internet of things IoT. Application of IoT in manufacturing industry is known as IIoT or Industrial Internet or Industry 4.0. IIoT will revolve manufacturing industries by providing unprecedented capability for massive, accurate and faster data acquisition and data processing. IIoT-

Industrial Internet of Things (figure 4) is next big thing. The above figure depicts four industry reforms namely Industry $1.0,2.0,3.0$ and 4.0. the latest industry reform is initiated by Germany and it is termed as Industry 4.0 or industrial internet. IIoT will bring unprecedented opportunities with new business risks. It will provide a new capability to Internet, this will be the ability to control the machines, infrastructures, factories.

The IIOT will transform [3] gas, mining, oil, healthcare, agriculture and transport industries. These industries account for two - third of the world economy.

\subsection{Benefits \& Opportunities of IIoT:}

The most important benefit of IIoT for mining, oil, gas, agriculture, manufacturing, healthcare sector is increase in revenue or cost cutting. The benefits of IIoT for industries on the basis of world economic forum industrial internet survey, 2014 are shown below in figure 5 .

World economic Forum Industrial Internet Survey was conducted in collaboration with Industrial Internet consortium (IIC) and Accenture. The survey was distributed to 250 market leaders, who are the members of Internet of Things world forum, industries 4.0, or IIC. All these participants are actively involved in the industrial internet development.

The results in figure 5 indicate that 79 percent companies are agree on the point that the adoption to IIOT will result in optimizing the asset utilization. 81 percent think that by adopting the IIoT, their industry will be able to reduce the operational cost. 74 percent companies agreed that IIoT will improve the employee productivity. 74 percent said that it will create new revenue through new products \& services.64 percent said that it will also enhance customer experience.

One more important benefit of IIoT is predictive maintenance. It will reduce unexpected failure of machinery and the breakdown as well. It will be possible because of the availability of the operational data through IoT. Thomas water, the largest drinking water supplier in UK [4] is using sensors and real time data to react an advance to situations like leakage, poor weather etc.

The government can also use IIoT. It will help in providing transparency on utilization of resources like water, energy, fertilizers. It will result in increase in accountability \& reduction in the waste.
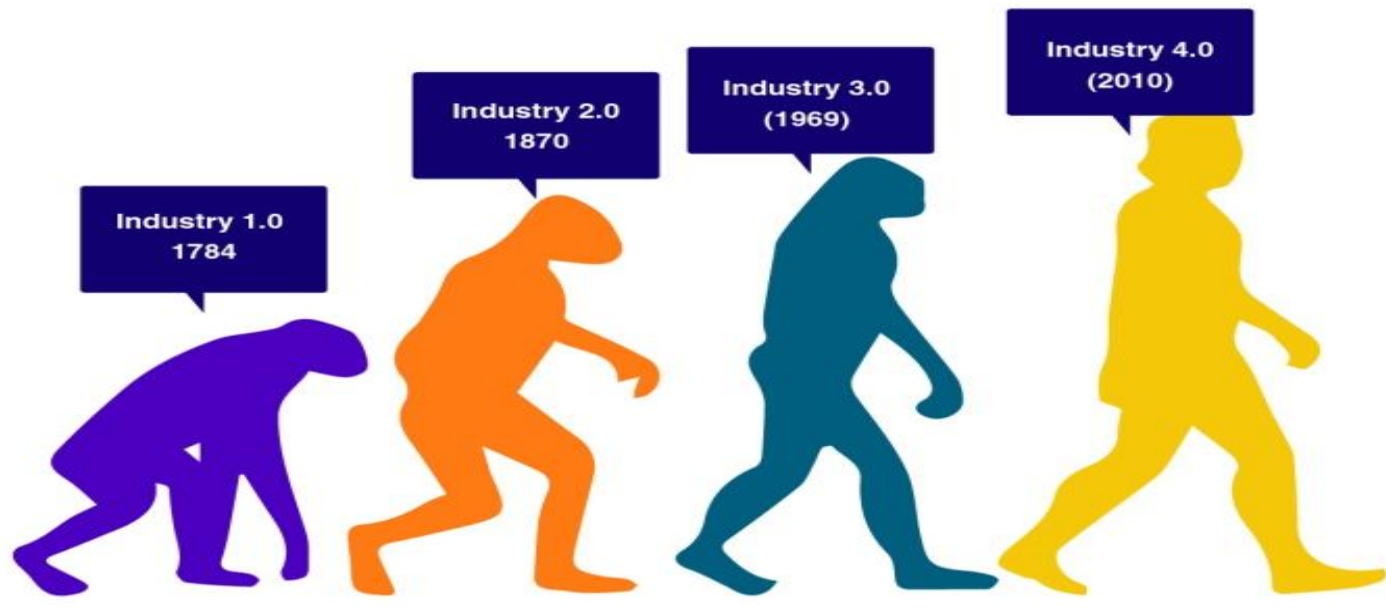

Fig 4: Industry 4.0 is the next leap in Industrial Automation driven by IoT 


\subsection{Challenges in Adaption of IIoT}

The challenges or barriers in adaption of IIoT for industries on the basis of world economic forum industrial internet survey, 2014 are shown below in figure 6.

Around two-third of the respondents told that the biggest worry is interoperability and security. Other barriers to IoT are uncertain return of investment, technology immaturity, lack of skilled labour etc. Some other potential barriers include, lack of leadership, lack of universal reference architecture, requirement of large investment, lack of proper business model, lack of infrastructure, cost of sensors.

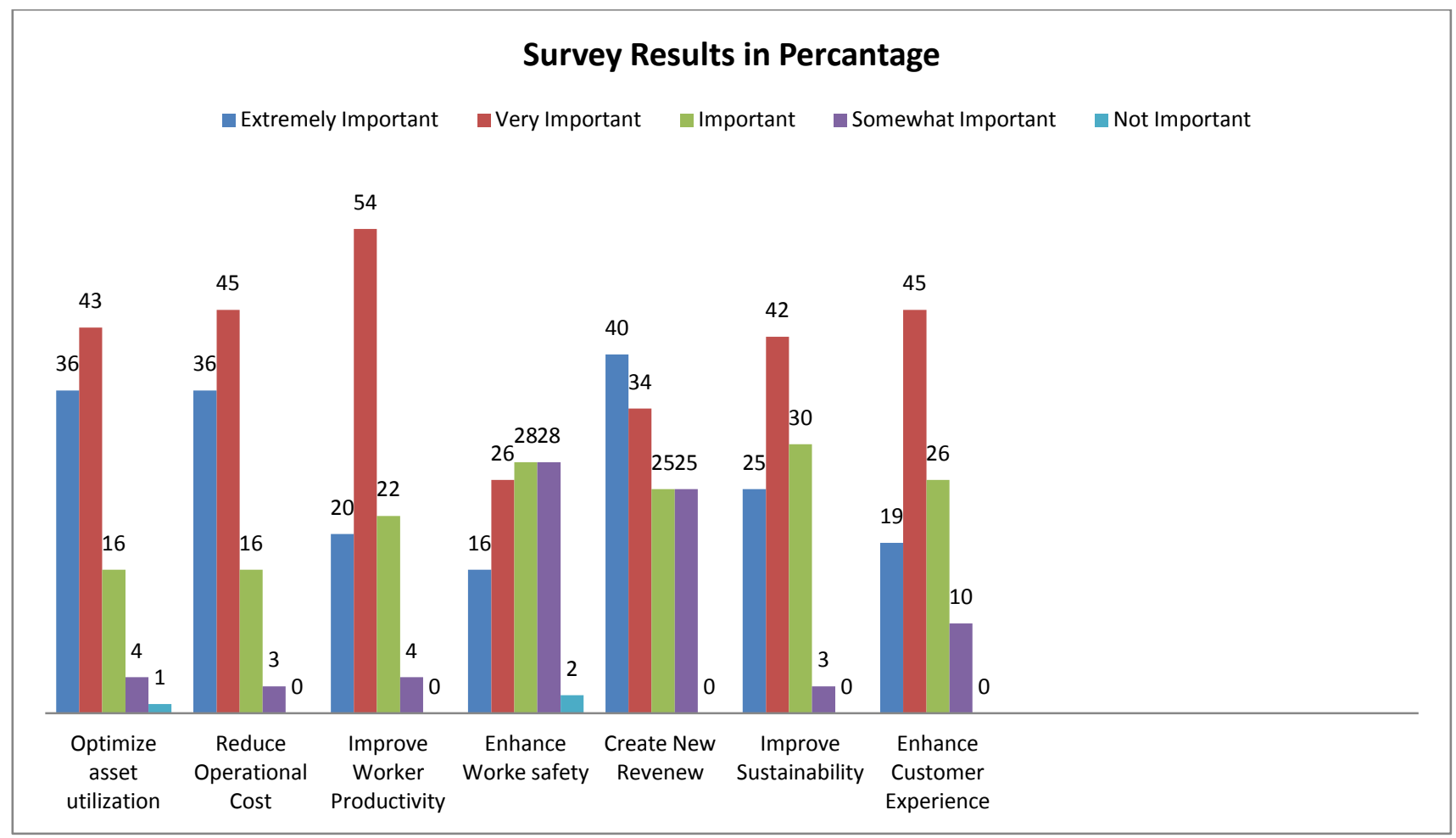

Fig 5: Benefits of IIoT [source: world economic forum industrial internet survey, 2014]

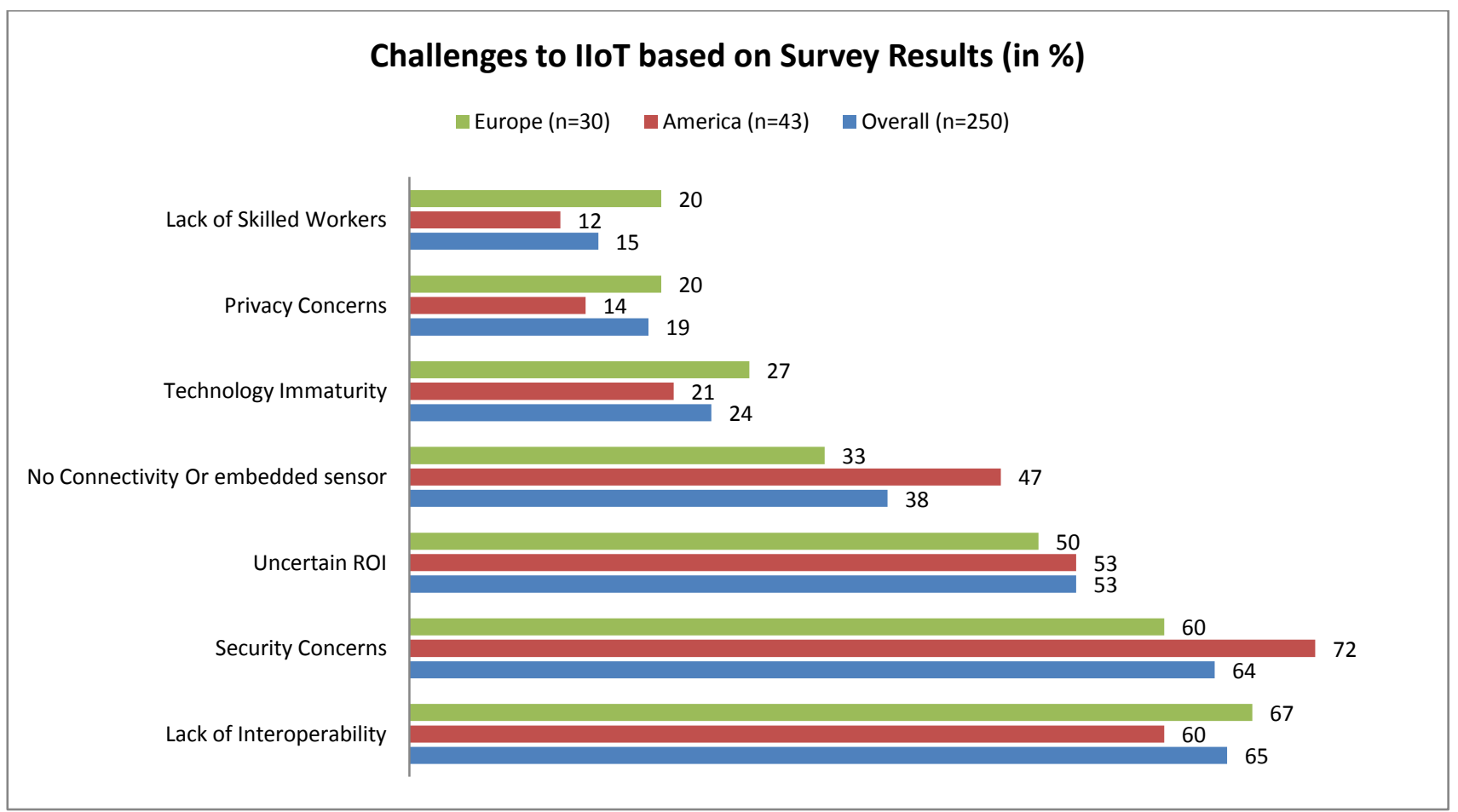

Fig 6: Barriers of IIoT [source: world economic forum industrial internet survey, 2014] 


\section{IIOT-CURRENT PROGRESS (IIOT IS TRENDING)}

Despite of all the barriers, the industrial internet has come up with flying colors in recent years. The number of sensors shipped [5] has increase by five times from 2012 to 2014 . The government of Germany has taken an IIoT initiative known as industrie 4.0. The second Internet of Things World Forum was organized by Cisco. The steering committee of the forum was comprising of 100 market leader companies. This forum showcased 250 real world examples of industrial internet applications. Organizations and municipalities around the world are using industrial internet to improve services, improve resource utilization, enhance customer experience, and to create new services to create new revenue. The second Internet of Things World Forum introduced a seven layer IoT reference model.

GE announced [6] that their revenue has increased by $\$ 1$ billion in 2014 by improving the business operations through IIoT. The government of China has also announced " Make in china 2025 " to promote integration of technology \& industries. The industrial internet has attracted a capital of $\$ 1.5$ billion [7] in 2014. Major funding for industrial internet comes from Cisco Investments, Intel Capital, Siemens Ventures, GE Ventures. Wireless sensors, low cost sensors and embedded systems are the key reasons for the exponential growth of the IIoT [8][9][10].

Smart city [11] [12][13]is a concept of providing a new set of services to consumer through information and communication technology (ICT). Smart city consist of many subdomain like: smart homes, smart energy, smart transportation, smart, energy, smart healthcare, smart building, smart education and smart industry automation. As per the reports of MarketsandMarkets, 14.2 percent annual increase in smart product sales is registered from 2011 to 2016.

IoT applications [14][15] are steel in their early stage. Only a few applications have been developed and deployed in industries like healthcare, agriculture, automobiles, transportation, security and surveillance. There are certain design goals [16], which are required to be considered while designing an IIoT application. These goals are listed below in Table 1.

Table 1: Design considerations for IIoT application development[16]

\begin{tabular}{|l|l|}
\hline Design Goals & Description \\
\hline Energy & $\begin{array}{l}\text { How long can an IoT device operate with } \\
\text { limited power supply? }\end{array}$ \\
\hline Latency & $\begin{array}{l}\text { How much time is needed for message } \\
\text { propagation and processing? }\end{array}$ \\
\hline Throughput & $\begin{array}{l}\text { What is the maximum amount of data } \\
\text { that can be transported through the } \\
\text { network? }\end{array}$ \\
\hline Scalability & How many devices are supported? \\
\hline Topology & Who must communicate with whom? \\
\hline Security \& Safety & How secure and safe is the application? \\
\hline
\end{tabular}

SIOT [17] Social Internet of things is a new paradigm, which was proposed by Atzori at al. It is based on the sense of using the social network sites for communication in Internet of Things (IoT). As we know that the implementation of Internet of Things (IoT) is possible only using the sensors. The deployment of such huge numbers of sensors will require result in a lot of power consumption. It is a matter of concern and also a barrier in the adaption of IoT. So there is a requirement to develop energy efficient techniques [18] [19] to save the power consumption of sensors.

Sensors spread around the globe are continuously sensing the data. This data is extremely voluminous. It is not possible to collect and process all data sensed by all the sensors. So there is a scope to develop context aware techniques [20] to decide what data is required to be collected and processed.

Arsino at al [21] makes use of artificial intelligence techniques to create intelligent Internet of Things. Future IoT systems [22][23][24] will be more smart and intelligent. They will be self optimizing, self organizing, self healing.

\section{CONCLUSION}

In this paper, we reviewed recent research going on in industrial internet to revolve fourth industrial reform Industry 4.0. Substantial research and development activities are going around the globe on industrial internet. In this paper, we made use of, world economic forum industrial internet survey, 2014 , for providing the benefits and challenges in adaption of IIoT. This paper also provided a list of design issues to be considered while designing an industrial internet application. Further research on standardization, lack of vision, quality of service, business model, and risk mitigation are required to flourish the industrial internet. It is found that a large number of peoples are concerned about security and privacy of their data in Internet of Things. In future, a lot of research is required to be done on security and privacy issues related to Internet of Things. It is also found that the Java will play a vital role in the implementation of Internet of Things. Java is secure $\&$ it has the ability to run on a wide range of devices. This paper is expected to be useful for researchers, policymakers and professionals of Industrial internet area.

\section{REFERENCES}

[1] Gartner, Hyper Cycles Research. 2014. http://www.gartner.com/technology/research/hypecycles.

[2] The 2017 Top Programming Languages http://spectrum.ieee.org/computing/software/top-10programming-languages

[3] Oxford Economics, https://www.oxfordeconomics.com/forecastsandmodels/industries/data-and-forecasts/global-industrydatabank/ benefits-and-uses.

[4] Woody, Todd. "Oil Giant to Launch Fleet of OceanGoing Robots". Forbes.com, June 12, 2012. http://www.forbes.com/sites/ toddwoody/2012/06/21/oilgiant-to-launch-fleet-of-ocean-going-robots.

[5] Elfrink, Wim. "The Internet of Things: Capturing the Accelerated Opportunity". Cisco Blog, October 15, 2014. http://blogs.cisco.com/ioe/ the-internet-of-thingscapturing-the-accelerated-opportunity.

[6] Cisco, 2014 IoT World Forum. http://www.iotwf.com. 6 GE press release. "GE to Open Up Predix Industrial Internet Platform to All Users". October 9, 2014. http://www.genewsroom.com/pressreleases/ge-openpredix-industrial-internet-platform-all-users-278755.

[7] Cisco, 2014 IoT World Forum. http://www.iotwf.com.

[8] S. Wang, J. Wan, D. Zhang, D. Li, and C. Zhang, Towards the smart factory for industrie 4.0: A self- 
organized multi-agent system assisted with big data based feedback and coordination Elsevier computer networks, Comput. Netw., vol. 101, pp. 158-168, Jun. 2016.

[9] S. Wang, J. Wan, D. Li, and C. Zhang, Implementing smart factory of industrie 4.0: An outlook, Int. J. Distrib. Sensor Netw., vol. 2016, Apr. 2015, Art. no. 3159805, doi: $10.1155 / 2016 / 3159805$.

[10] F. Chen, P. Deng, J. Wan, D. Zhang, A. Vasilakos, and $X$. Rong, Data mining for the Internet of things: Literature review and challenges, Int. J. Distrib. Sensor Netw., vol. 2015, Mar. 2015, Art. no. 431047, doi: $10.1155 / 2015 / 431047$

[11] G. Kortuem, F. Kawsar, D. Fitton, and V. Sundramoorthy, "Smart objects as building blocks for the Internet of Things," IEEE Internet Com- put., vol. 14, no. 1, pp. 44-51, Jan./Feb. 2010. [Online]. Available: http://dx.doi.org/10.1109/MIC.2009.143

[12] A. Zanella, N. Bui, A. Castellani, L. Vangelista, and M. Zorzi, "Internet of Things for smart cities," IEEE Internet Things J., vol. 1, no. 1, pp. 22-32, Feb. 2014.

[13] C. Perera, A. Zaslavsky, P. Christen, and D. Georgakopoulos, "Context aware computing for the Internet of Things: A survey," IEEE Commun. Surveys Tuts., vol. 16, no. 1, pp. 414-454, Jan. 2013

[14] W. Viriyasitavat, L. Xu, A. Martin, "SWSpec, service workflow requirements specification language: the formal requirements specification in service workflow environments," IEEE Transactions on Industrial Informatics 8 (3): 679-687, 2012.

[15] L. Xu, "Enterprise Systems: state-of-the-art and future trends," IEEE Transactions on Industrial Informatics, vol.7, no.4, pp. 630-640, 2011.

[16] C. Flügel, and V. Gehrmann, "Scientific workshop 4: intelligent objects for the Internet of Things: Internet of Things-application of sensor networks in logistics,"
Communications in Computer and Information Science, vol.32, pp.16-26, 2009.

[17] L. Atzori, A. Iera, G. Morabito, and M. Nitti, "The social Internet of Things (SIoT) when social networks meet the Internet of Things: concept, architecture and network characterization," Computer Networks, vol.56, no.16, pp. 3594-3608, 2012.

[18] F. Xia, "Wireless sensor technologies and applications," Sensors, vol.9, no.11, pp.8824-8830, 2009.

[19] E. Yaacoub, A. Kadri, and A. Abu-Dayya, "Cooperative wireless sensor networks for green internet of things," in Proceedings of the 8h ACM Symposium on QoS and Security for Wireless and Mobile Networks, pp. 7980, ACM, 2012

[20] S. Wang, Z. Zhang, Z. Ye, X. Wang, X. Lin, and S. Chen, "Application of environmental Internet of Things on water quality management of urban scenic river," International Journal of Sustainable Development \& World Ecology, vol.20, no.3, pp.216-222, 2013.

[21] A. Arsénio, H. Serra, R. Francisco, F. Nabais, J. Andrade, and E. Serrano, "Internet of Intelligent Things: bringing artificial intelligence into things and communication networks," Studies in Computational Intelligence, vol.495, pp.1-37, 2014.

[22] J. O. Kephart, and D. M. Chess, "The vision of autonomic computing," IEEE Computer, vol.36, no.1, pp.41-50, 2003.

[23] G. Kortuem, F. Kawsar, D. Fitton, and V. Sundramoorthy, "Smart objects as building blocks for the internet of things," IEEE Internet Computing, vol.14, no.1, pp.44-51, 2010.

[24] Y. Ding, Y. Jin, L. Ren, and K. Hao, "An intelligent self-organization scheme for the Internet of Things," IEEE Computational Intelligence Magazine, vol.8, no.3, pp.41-53, 2013 